\title{
Lily L. Tsai, Accountability Without Democracy: Solidary Groups and Public Goods Provision in Rural China (Cambridge University Press, 2007), 368p, £21.99, ISBN 9780521692809
}

\author{
Yao Han $^{1,2}$ (D)
}

Received: 18 May 2016/ Accepted: 12 June 2016/Published online: 20 June 2016

(C) Fudan University and Springer Science+Business Media Singapore 2016

Lily L. Tsai is currently an associate professor of political science at MIT. Her book, Accountability without Democracy: Solidary Groups and Public Goods Provision in Rural China, attempts to answer why government officials provide public goods more than needed for social stability when they are less constrained in authoritarian and transitional systems. This book first presents the profile of China's local governance and public goods provision influenced by the dramatic economic and political reforms to give the readers a broad view of the context. Then, it explains why accountability exists when there is no formal democracy. It is argued by that solidary groups create informal ties and exert soft power on the local officials making them embedded in the solidary groups and feel obliged to provide public goods and services without institutionalized democracy.

The book uses case studies to construct the causal mechanism and to search for deeper explanations of the heterogeneity of the forms of the solidary groups. Specifically, the book harnesses both quantitative and qualitative methods to enhance the reliability and validity of its theory. By quantitative methods, this book collects data using questionnaires containing both objective and subjective questions in 316 villages in the four provinces selected (Shanxi, Hebei, Jiangxi and Fujian). A seemingly unrelated regression (SUR) model is used to test the causal relationships, endeavoring to measure the provision of public goods and services by local government more concretely and to validate the explanatory model. By qualitative methods, this book takes advantage of in-depth interviews

Yao Han

hanyao.sara@yahoo.com

1 School of Politics and International Relations, University College Dublin, Dublin 4, Dublin, Ireland

2 Geary Institute for Public Policy, University College Dublin, Dublin 4, Dublin, Ireland 
during the survey to explore strong evidence of the provision of public goods and services and better understanding about how the solidary groups take effect.

Lily L. Tsai puts the research in the context of the discussion of a central-local governmental relationship in China. When dealing with the accountability of local government, the allocation of the financial and administrative responsibilities among different levels of government that change over time needs to be clarified and the boundaries of can-do and should-do for the local government to be set. So the book briefly sketches the institutional context during the research period, characterized by decentralization which means that the central government decentralizes both the financial and administrative responsibilities to the local government. Part of the result is the lack and/or the difficulty of supervision for the local government of both the financial and administrative aspects by the central government.

The other important background of this book is the massive adoption of electoral systems in rural China since the 1980s (Zhang et al. 2004). According to the observation of this book, not all villages have completed their institutionalization of their electoral systems.

The book uses the existence of temples and churches and their managers as a symbol for the influence of solidary groups. In chapter 4, the book details the interaction between the local government, the council of the temple and villagers in the West Gate Village Case in Fujian province. From Lily L. Tsai's perspective, such interaction explains the better provision of the public goods by the government. However, what I saw from this interaction is different.

On the one hand, I agree with Lily L. Tsai that the existence of solidary groups helps to improve the governmental performance in terms of public goods provision, but using temples and churches as the proxy indicators may be a bit narrow. The sample size is relatively small compared to the population, though Lily L. Tsai tries to use survey data and a seemingly unrelated regression (SUR) model to validate the model. There are 678,589 administrative villages in mainland China in 2003 compiled by the National Bureau of Statistics in the 2004 Statistical Yearbook ${ }^{1}$ (Tsai 2007): 316 villages only make a proportion of near $0.47 \%$. The representativeness of the samples for the population is not convincing. Besides, not all the temples are active as real "temples" in villages. In some villages, the temples are built as a kind of traditional architecture for attracting visitors and boosting tourism. Then, temples in fact belong to a kind of infrastructure invested in by the government which may cause an endogenous problem in the regression method. For the villages where temples and churches do operate as the home of human spiritual pursuit, the extent of their influence on local government and villagers varies and their impact on forming solidary groups is different as well. For some villages, it is proper to equate the solidary groups with the groups formed by the effects of temples and/or churches, while for other villages, it is not proper to label temples and/or churches as types of solidary groups, as there may be other factors helping to form the groups in these villages including traditional moral standards, the influences of the belief in communism, etc. It is good for Lily L. Tsai to compare

${ }^{1}$ pp. 29. 
temples and churches as two types of solidary groups with similarities in their encompassing and with differences in their embeddedness to test the effect of the solidary groups on the village governmental provision of public goods. But, it also creates blocks in the way of its high external validity. The indicators chosen have limitations, though the book tries to use survey data to help build a more general theory. Due to the limitations of both the sample representativeness and the appropriateness of the indicators, the research in this book might well suit itself in some particular contexts. The primary points raised by this book that solidary groups have a positive effect on public goods provision in rural China are more generalized.

The book tries to find the variables which help form village-wide solidary groups that have enough power to influence the provision of public goods and services. The temple is a kind of organization with such effects, and village-wide lineages are of another kind. One of the contributions of the book is to distinguish those aspects from the manifestations of the obscure concepts of solidary groups. However, it is difficult for the book to name all the manifestations, and it is also hard to identify the latent variables such as share values.

On the other hand, the interaction among local governments, the council of temples and villages outlined by Lily L. Tsai is very thought provoking. The interpretation of the interaction among the three parties can vary broadly. For example, one interpretation of the interaction and the good provision of public goods by the local government is that the temples are tools for local governments to collect money from villagers as they survive on donations. Instead of being a part of villagers, the local governments make the use of villagers' beliefs in temples to have them abide by their mandates. The better provision of public goods is only another means of achieving this. Besides, the temples can be above the local government in villages and have great power in influencing both local governments and the villagers. In some cases, the temples may operate like an association, helping villagers maintain and demand their interest from local governments. And in other cases, the temples, local governments and villagers may form as a whole solidary group. It will be meaningful not only to look into the relationship between informal and formal institutions, but also specifically to the pattern of the modern relationship among religious institutions, governments and citizens and to the evolution of the interaction among them or to the interactions among beliefs or moral norms, governments and citizens.

In addition, the cases in this book illustrate another interesting phenomenon for the readers. That is, the economic development level of the villages seems to be associated with the development level of democratic and bureaucratic institutions. Does it prove that economic development comes before the development of democracy?

"In Jiangxi province, High Mountain and Li Settlement are both poor with poorly implemented democratic and bureaucratic institutions of accountability - yet Li Settlement somehow manages to fund and organise public projects. In Fujian province, West Gate and Three Forks are both wealthy with well- 
implemented democratic and bureaucratic institutions - yet only West Gates'

officials provide public goods and services conscientiously."2 (Tsai 2007).

The four cases also show different levels of governance measured by the level of provision of public goods and services. Relating it to the development strategy proposed by Deng Xiaoping from the mid-1980s, the question arises: in which situation the governance will keep good or get rid of bad performance when the economy develops with part of the people becoming wealthy? Besides, is there any dynamic sequence of the four scenarios represented by the four cases? For example, will the economic development and democratisation finally lead to good governance?

The book provides some clues to the research in several research strands. One is about the discussion of the longevity of a country with different political regimes. China is a country considered by the rest world as one without democracy. It can be inferred that a non-democratic country could hardly provide enough public goods to citizens and will be difficult to live long. However, China still exists as an autocratic country in western eyes with fast economic growth, which poses an enigma to the rest world. Lily L. Tsai contributes to the answer by finding that there exist villages that manage to provide good public infrastructure without democracy and further enrich the understanding of the autocratic China by explaining the causal mechanism of accountability without democracy. Another strand is to evaluate the quality of democracy through evaluating the governance or governmental performance. The book also looks into why and how villages with institutionalized democracy fail to provide solid public goods. In other words, those villages offer good opportunities to observe fake democracy under which a small group of people grasp the power and institutionalize their benefit in the form of mature election procedures while providing public goods insufficiently to the public. The fake democracy may be an epitome of many democratic countries in the world. On the way of democratization, such a kind of democracy poses more threats to the steadiness of a country than the case with the good provision of public goods and services although without democracy. If a country marches towards democracy of this kind, the day when it finalizes the democratization process is the day when it collapses.

Besides, this book contributes to the theory of state-civil society relationship by responding well to the research of Ostrum in long-surviving and self-organized resource regimes. The key commonality between them is their emphasizing the effect of norm in helping a closed regime to develop its self-provision mechanism.

In all, this book starts with the question why villages of the same economic development level are of different level in public goods provision and narrows down the puzzle to the relation between democracy and public goods provision in rural China. Then, it constructs the explanatory model and validates the model using well-developed mixed methods and ends with the findings of the effects of solidary groups as an informal mechanism on the accountability of governments and finally broadens the findings in the hope of arousing attentions to:

2 pp. 3. 
"the interactions between informal and formal institutions, social structures and state structures, and social boundaries and political boundaries in ways that improve our understanding of governmental performance and public goods provision in many other places"3 (Tsai 2007)

except for rural places in China.

This book raises an interesting question and answers it in a solid way combining qualitative and quantitative methods. The methods developed by this research create a good example in social sciences. The survey data analysis helps readers to establish concrete understandings of the situation and the mechanism, while the indepth interview not only helps the writer discover the mechanism and provides vivid evidence for the readers but also unveils many interesting phenomena, thus creating lots of possible research directions. However, the book is still limited in more generalized evidence when building and validating the theory. It leaves some gaps to be replenished by some empirical research (e.g., the research on self-governing social organisations and public goods provision (Pesqué-Cela et al. 2009).) and opportunities for researchers to build more encompassing theories using more systematic evidence or starting from other contexts.

Acknowledgments I wish to thank Paul D. Kenny and Johan A. Elkink for the comments on the earlier drafts and Michael Kaeflein for his proofreading and editing.

\section{References}

Pesqué-Cela, Vanesa, Ran Tao, Yongdong Liu, and Laixiang Sun. 2009. Challenging, complementing or assuming 'the Mandate of Heaven'? Political distrust and the rise of self-governing social organizations in rural China. Journal of Comparative Economics 37(1): 151-168.

Tsai, Lily L. 2007. Accountability without democracy: Solidary groups and public goods provision in rural China. Cambridge: Cambridge University Press.

Zhang, Xiaobo, Shenggen Fan, Linxiu Zhang, and Jikun Huang. 2004. Local governance and public goods provision in rural China. Journal of Public Economics 88(12): 2857-2871.

Yao Han is a $\mathrm{PhD}$ researcher at Geary Institute for Public Policy at University College Dublin and PhD candidate at School of Politics and International Relations at University College Dublin.

3 pp. 25. 